\title{
Metadiscourse Use in a Dialogic Feedback Practice*
}

\author{
Claire Louise Rodway ${ }^{1}$ \\ Griffith University
}

\begin{abstract}
A socio-constructivist approach to writing pedagogy recognises the importance of participant relationships in argumentation in disciplinary writing, although awareness of the rhetorical resources available to achieve this dialogic partnership between writer and reader can be difficult to teach. The highly metadiscursive nature of feedback commentary, however, offers the potential to scaffold such learning as part of a dialogic feedback cycle. Taking as its starting point, the concept of feedback as genre, this study investigated metadiscourse use in feedback data from the researcher's own teaching practice. A corpus of 627 formative comments, comprising 16,660 words and providing feedback on argumentation in first-year undergraduate texts, was analysed with reference to Ädel's $(2017,2018)$ recent findings and observations, which called for a re-defining of the function and definition of metadiscourse. Findings from the current study include a similarly high frequency of metadiscourse use in feedback to that found in Ädel's work and corroborate the validity of her suggested multidimensional model of metadiscourse. Additionally, examples from the corpus show the complexity and fluidity of the writer and reader roles. Frequencies of types of metadiscourse markers varied depending on purpose, reflecting either the response of "teacher as reader and dialogue partner" or the pedagogical response of "teacher as knowledge resource". Responses worked "intratextually" and "intertextually" by extensively referencing both "current text" and earlier stages of the wider feedback discourse chain when identifying and providing rationale and resolution for problems in the development of argument in the text.
\end{abstract}

\section{Keywords}

Feedback • Argumentation • Second language writing • Metadiscourse use in feedback • Writing pedagogy

\footnotetext{
* This paper was revised after being presented at the conference Metadiscourse Across Genres, Middle East Technical University, North Cyprus, 30th March - 1st April 2017

1 Correspondence to: Dr Claire Louise Rodway, School of Humanities, Languages and Social Science, Griffith University, Parklands Drive, Southport, Qld 4215 Australia. Email: c.rodway@griffith.edu.au

Citation: Rodway, C. L. (2018). Metadiscourse use in a dialogic feedback practice. Educational Sciences: Theory \& Practice, 18, 797-812. http://dx.doi.org/10.12738/estp.2018.4.0043
} 
Participant relationships are crucial elements of argumentation in disciplinary academic writing. Writers have discursive responsibilities to their readers which require them to position and construct a dialogic partnership with an audience based on their assumptions about, and awareness of, their readers' expectations, needs and rhetorical preferences (Aull \& Lancaster, 2014; Hyland, 2001, 2005b; Swales, 1990), demonstrating both subject knowledge and successful development of argument. Text, therefore, needs to be understood as not only propositional information, but also in terms of the relationship between those ideas, and between writer, reader and the surrounding text as it unfolds and develops (Hyland, 2005a, 2016). This socioconstructivist and reader-oriented approach to writing (Hyland, 2016), however, can be challenging for novice writers, especially second language writers, where a previously experienced text-oriented approach with focus on accuracy can distance the writer from their role as participant. This can result in writing that fails to realise "internal" argument or criticality and the dialogic awareness required to enable the reader to cohere the intended line of reasoning (Bublitz, 1999; Hyland, 2004). Promoting this awareness of the dialogic partnerships that are so key to successful argumentation through pedagogy, however, can be difficult.

Despite the well-documented central role of feedback provision in writing pedagogy, providing feedback in the context of a course that proposes to develop and evaluate both language proficiency and academic literacy skills is complex. In their roles as feedback providers, teachers have to address language issues both above and below clause and sentence level, as well as those related to subject content and research. In this context, when the reader is typically positioned in a role as "assessor" of language accuracy, the concept and implications of writing as a social action, dependent on interaction between writer and reader, can be especially difficult to "get across" in the classroom (Goldstein, 2005). Argumentation or the "process of arguing" (Andrews, 2010) in academic writing requires the maintenance of this dialogic interaction with audience, however. For second language writers, focusing on support for an argument, rather than its development, can lead to writing that lacks criticality and analysis (Bacha, 2010; Rodway, 2017b; Wingate, 2012). Prior instruction which may have oversimplified argument development can elide the importance of these interpersonal or metadiscoursal elements of writing (Hyland, 2005a) in fully developing and progressing an idea. This can be evidenced in problems such as failure to justify support, weak internal argument with an overuse of transition signals to order propositional material rather than develop argument, and a lack of criticality with an overreliance on attribution resulting in descriptive rather than analytical writing (Rodway, 2017b). As the realisation of interactions between writer and reader, metadiscourse markers explicitly "organise a discourse or the writer's stance towards either its content or the reader" (Hyland, 2005a, p. 4), relating text to context by directing readers to retrieve the preferred organisation, connections and interpretations of the writer. 
Annelie Ädel (2017), in her recent article "Remember your reader cannot read your mind", has drawn attention to the metadiscursive features of feedback on student writing (see also Ädel, 2018). Her corpus analysis of comments from five teachers on 375 student assignments revealed the problem/solution orientation of metadiscourse in feedback which is different to the typically discourse-organising function of metadiscourse in academic writing. Ädel (2017) suggests "[i]t is as if the teachers are evaluating whether the [communication] channel is working not so well or very well ... to see to it that the text communicates what (they believe) it is intended and supposed to communicate" (p. 64). It is precisely this highly metadiscursive nature of feedback that gives it the potential to communicate the response of a reader (in addition to that of teacher or "knowledge resource") to the unfolding line of argument. In other words, a dialogic writer/reader interaction, with student and teacher assuming both roles, is mediated through feedback comments. This type of interactional dialogic written commentary feedback can function as a form of "metasemiotic mediation" (Coffin \& Donohue, 2014), scaffolding deep reflection and, in turn, interactive dialogic texts. This is realised in the metadiscursive features of the feedback comments themselves, articulating where an intended line of argument breaks down, and rationale and resolution for the problem. Within a dialogic framework, such feedback functions intratextually referencing the "current" text and intertextually referencing the wider feedback discourse which, although outside of the current text itself, comprises elements in the feedback process.

\section{Method}

\section{Research Design}

In this study, analysis of metadiscourse use in written commentary feedback on argumentation was carried out as part of a larger practitioner inquiry to develop a praxiology (Elliot, 1991), or principled framework for a dialogic feedback practice. This framework was based on an adaptation of Beaumont, Shannon, and O'Doherty's (2011) Dialogic Feedback Cycle and Hammond and Gibbons's (2005) interactional contingent scaffolding model as shown in Figure 1. Here, feedback as a "supporting genre" (Ädel, 2017) operates across three phases of a cycle: preparatory guidance, in-task guidance and performance feedback. At the macro level, active participation of both student and teacher is encouraged to promote dialogic feedback and feedback literacy in the wider context of feedback discourse. Within this macro cycle, dialogic feedback scaffolds at a micro level to realise improvements to students" argumentational skills of the current text. 


\section{PREPARATORY GUIDANCE}

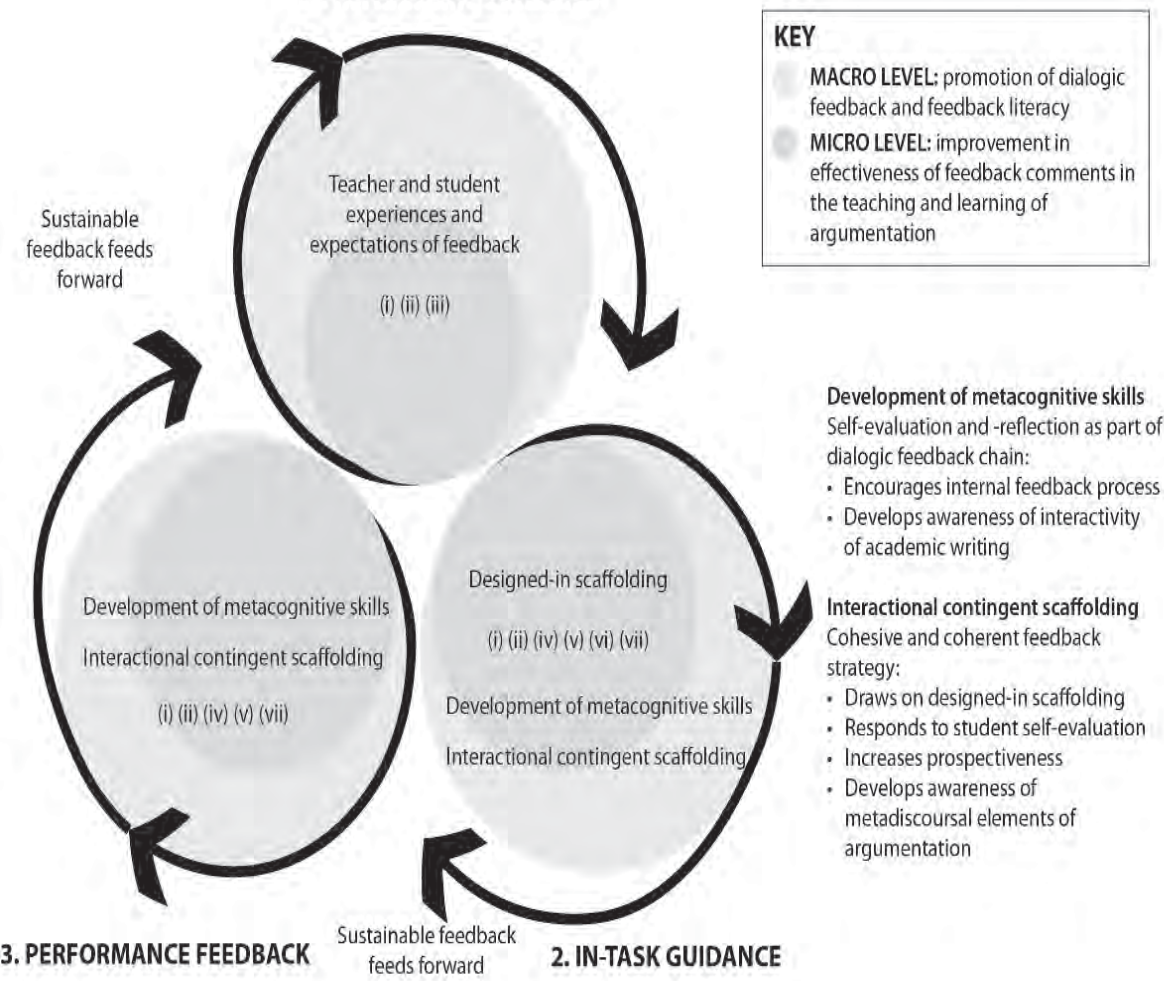

Figure 1. A framework for written commentary feedback within a dialogic feedback cycle.

At both macro and micro level, metadiscourse functions to realise interaction between writer and reader (whether as writer of feedback and/or original text or reader of feedback/original text) as participating members of a feedback discourse community. Practical strategies were designed to operationalise seven theoretical principles across the three phases of the cycle. These principles were:

(i) Effective written commentary feedback should be dialogic and collaborative

(ii) Dialogic feedback can help to bring awareness of the interactive nature of academic writing

(iii) Expectations of feedback need to be managed

(iv) Effective feedback strategies should promote self-reflection and selfassessment for and as learning

(v) Feedback that supports students working within their ZPD can best facilitate improvements in argumentation 
(vi) Metadiscoursal awareness is key in successful argumentation

(vii) Dialogic written commentary feedback can be used to scaffold metadiscoursal awareness

In Hammond and Gibbons's (2005) model, interactional contingent scaffolding is conceptualised as being the unplanned teacher-student dialogue that occurs in the classroom. Elements of this model, however, can also be realised through dialogic written commentary feedback. These elements are increasing prospectiveness and linking to prior experience/pointing forward. In the Initiate Respond Feedback (IRF) sequence of moves in the classroom, feedback can be used to request clarification, encourage explanation, and reflect on thinking, drawing on the planned or "designedin" (Hammond \& Gibbons, 2005) scaffolding of prior learning and teaching. In this way, the teacher "returns" the responsibility to continue dialogue back to the student, thereby "increasing prospectiveness", a term Hammond and Gibbons take from Wells (1996). Written commentary feedback that is dialogic can also function in the same way to scaffold students' awareness and understanding of the interactive and interpersonal qualities of argumentation in their writing, reflecting a reader's and teacher's response to the text as both dialogue partner and knowledge resource. In the adapted cycle, feedback also draws explicitly on the designed-in scaffolding from classroom instruction. Such pedagogy is aimed at increasing awareness of the metadiscoursal elements of argumentation following this researcher's socio-constructivist approach to teaching writing. This forms part of the context at the micro level, realising supporting feedback discourse in the in-task guidance phase of the cycle.

\section{Corpus Materials and Analysis}

A small corpus of 2,087 feedback comments was compiled from 49 written assignments from two first-year first semester tutorial classes - Language and Communication for Business (comprising twenty-six students - Semester 22015 [LCBSem22015]) and Language and Communication for Arts and Social Sciences (comprising twenty-three students - Semester 12016 [LCASSem12016]). These full credited courses are integrated into existing programmes within each of the university's major academic groups and designed to improve international students' language and academic literacy skills (see Fenton-Smith, Humphreys, \& Walkinshaw, 2017; Fenton-Smith, Humphreys, Walkinshaw, Michael, \& Lobo, 2015). These are compulsory core courses for EAL [English as an additional language] students, who come via a range of pathways including high school entry, IELTS testing or similar, diploma, or a direct entry pathway from the university's language school. Their language proficiency levels were similar (ranging from an IELTS 6 (or equivalent), which was the university's minimum entry requirement at the time of the study, to an IELTS 6.5 (or equivalent)). The main written assessment task on these courses 
required students to write a research essay, submitted initially as a draft in week 7 , on which students received formative feedback only, and then again in week 11, at which point the task was graded. Both feedback and grading were focused on four criteria: task fulfilment, coherence and cohesion, grammar, and vocabulary.

Feedback was provided electronically by the researcher as course tutor through Turnitin's Grade Mark facility. In this computer-mediated feedback facility, sentencelevel form-focused lexical and syntactic errors were identified using indirect coding (e.g. VF to indicate an error with verb form), which included an explanation of the error and a hyperlink to further information. This type of written corrective feedback was not included in the present data analysis. Written commentary was provided as margin and as overall comments categorised by criterion in a "text comment" box (see Figure 2). In all data, students' names have been redacted or a pseudonym has been used.

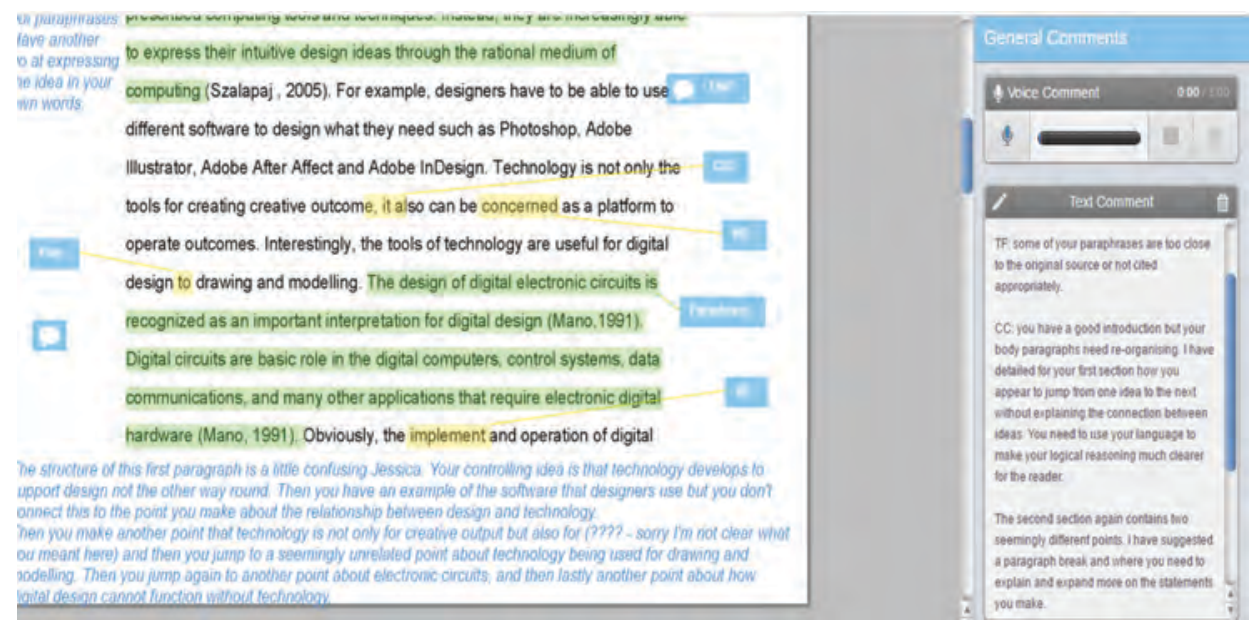

Figure 2. Screenshot of feedback comments in Turnitin's GradeMark facility.

A strategy was adopted by the researcher to provide feedback as interactional contingent scaffolding, drawing from a typology from Mahboob (2015), in which the degree of explicitness and/or rationale is modified in line with students' individual needs. This external feedback was just one stage of a feedback process initiated by the student's own internal feedback articulated through an interactive self-evaluation cover sheet based on principles of assessment as learning ${ }^{2}$ (see Rodway, 2017a for more details). This complexity of feedback as both "(i) a comment on the current text and (ii) a text in its own right" Ädel (2017, p. 64) suggests, means that it can be described as a "genre chain" (p. 65) feeding "back" as well as "forward". Such a process mediates a co-construction and negotiation of meaning between participants

2 Rodway (2017a) evaluates the effectiveness of an interactive self-evaluation essay cover sheet developed for student and teacher reflections as part of a supporting feedback framework. 
in this feedback discourse. Metadiscourse in other elements of the process, such as the interactive cover sheet, is not analysed in this paper. Figure 3 illustrates the "links" in the feedback chain and the reciprocal writer/reader roles for both student and teacher in the process.

\begin{tabular}{|c|c|c|c|}
\hline $\begin{array}{l}\text { Interactive self- } \\
\text { evaluation cover sheet } \\
\text { (internal feedback) }\end{array}$ & $\begin{array}{l}\text { Teacher formative } \\
\text { comments on draft } \\
\text { (external feedback) }\end{array}$ & $\begin{array}{l}\text { Student (internal) } \\
\text { reflection on } \\
\text { external feedback }\end{array}$ & $\begin{array}{l}\text { Final submission } \\
\text { (summative } \\
\text { external feedback) }\end{array}$ \\
\hline $\begin{array}{l}\text { Student/reader } \\
\text { Student/writer }\end{array}$ & $\begin{array}{l}\text { Teacher/reader } \\
\text { Teacher/writer }\end{array}$ & $\begin{array}{l}\text { Student/reader } \\
\text { Student/writer }\end{array}$ & $\begin{array}{l}\text { Teacher/reader } \\
\text { Teacher/writer } \\
\text { Student/reader }\end{array}$ \\
\hline
\end{tabular}

Figure 3. Feedback chain with reciprocal roles for discourse community members.

\section{Data Analysis}

An initial corpus of 2,087 formative feedback comments was compiled from the researcher's feedback on the 49 draft assignments from the two classes LCBSem22015 $(n=26)$ and LCASSem12016 $(n=23)$. Table 1 shows the breakdown for this across the two classes, with totals for each marking criterion.

Table 1

Feedback Corpus $(N=2087)$

\begin{tabular}{lcccccc}
\hline Class & $\begin{array}{c}\text { Average word length } \\
\text { per assignment }\end{array}$ & No. of comments & TF & CC & GRA/V & Other** \\
\hline LCBSem22015 & 928 & 1129 & 230 & 331 & 517 & 51 \\
LCASSem12016 & 605 & 958 & 108 & 353 & 459 & 38 \\
Totals & 776 [average] & 2087 & 338 & 684 & 976 & 89 \\
\hline
\end{tabular}

Note. Task requirements allowed students to submit work in progress or a complete essay. Draft length varied, therefore, between 250 and 1000 words per text.

Note. ** Generalised evaluative comments such as "Well done" or "This is disappointing" were coded as Other.

From this initial corpus, two sub corpora were extracted, which comprised only embedded in-text feedback comments that were related to argumentation (as rated by the researcher as teacher and feedback provider). One of these, AFBK1, which contained argumentation feedback comments from all drafts $(n=627)$, is the subject of this paper. Positive comments were included in this corpus where they offered "specific praise" (Vines, 2009), (i.e. implicit signalling to apply what has been done well to other paragraphs). A written feedback comment is defined here as one or more clauses/sentences relating to one issue. For example, "Your analysis and discussion of Burns's leadership styles needs much more referenced support to convince the reader. Try to find more specific examples of her styles 'in action" " was coded as one comment expressing problem/solution and rationale for the issue of use of sources. Comments relating to argumentation were grouped in categories as shown in Table 2. 
Table 2

Argumentation Categories

\begin{tabular}{|c|c|c|}
\hline Categories of argumentation & $\begin{array}{l}\text { Number of } \\
\text { comments }(\mathrm{N}=627)\end{array}$ & Examples from corpus \\
\hline Organisation of ideas & $181(29 \%)$ & $\begin{array}{l}\text { You need some background information here to } \\
\text { contextualise the topic before you move into your thesis } \\
\text { statement. } \\
\text { I need a topic sentence here with a controlling idea so I } \\
\text { know what this paragraph is about. }\end{array}$ \\
\hline Logical reasoning & $141(22 \%)$ & $\begin{array}{l}\text { You haven't made any connection between that and } \\
\text { productivity. In other words, you need to develop this } \\
\text { point with examples of what she did to actualise this } \\
\text { belief and how that benefited the organisation to enable } \\
\text { me to see how you draw this conclusion. }\end{array}$ \\
\hline Developing ideas & $104(17 \%)$ & $\begin{array}{l}\text { I think you need to more fully explain "internal } \\
\text { variations" for this to be a logical progression of your } \\
\text { argument Becky. }\end{array}$ \\
\hline Use of sources & $101(16 \%)$ & $\begin{array}{l}\text { Your analysis and discussion of Burns's leadership styles } \\
\text { needs much more referenced support to convince the } \\
\text { reader. Try to find more specific examples of her styles } \\
\text { "in action". }\end{array}$ \\
\hline Logical connectives & $100(16 \%)$ & $\begin{array}{l}\text { You need to link these two points more explicitly if there } \\
\text { is a connection Miko. }\end{array}$ \\
\hline
\end{tabular}

Note. Task requirements allowed students to submit work in progress or a complete essay. Draft length could vary, therefore, between 250 and 1000 words per text.

Note. * feedback comments on argumentation categories

Analysis of the metadiscoursal markers in the feedback comments was carried out on corpus AFBK1 $(n=627)$. Frequency data for this corpus, including number of tokens, are shown in Table 3. Frequency data for corpus AFBK1 and for Ädel's (2017) feedback corpus material are presented together in Table 4 for comparison. Ädel's corpus material comprised written comments from five teachers; averages from this corpus, therefore, are shown in the comparison data.

Table 3

Overall Frequency Data for Argumentation Feedback Corpus AFBK1

\begin{tabular}{lccccccc}
\hline Class & $\begin{array}{c}\text { No. } \\
\text { of } \\
\text { texts }\end{array}$ & $\begin{array}{c}\text { Average } \\
\text { word } \\
\text { length } \\
\text { per text }\end{array}$ & $\begin{array}{c}\text { No. of } \\
\text { comments* }\end{array}$ & $\begin{array}{c}\text { \% of total no. } \\
\text { of comments } \\
(\mathrm{N}=2087)\end{array}$ & $\begin{array}{c}\text { Average no. } \\
\text { of comments* } \\
\text { per text }\end{array}$ & $\begin{array}{c}\text { No. of } \\
\text { tokens** }\end{array}$ & $\begin{array}{c}\text { Average no. } \\
\text { of tokens** } \\
\text { per comment }\end{array}$ \\
\hline LCBSem22015 & 26 & 928 & 303 & 14.5 & 12 & 4,760 & 16 \\
LCASSem12016 & 23 & 605 & 324 & 15.5 & 14 & 11,900 & 37 \\
Totals & 49 & $\begin{array}{c}776 \\
\text { [average] }\end{array}$ & 627 & 30 & 13 [average] & 16,660 & 27 [average] \\
\hline
\end{tabular}

Note. Task requirements allowed students to submit work in progress or a complete essay. Draft length varied, therefore, between 250 and 1000 words per text.

Note. * argumentation feedback comments; **number of tokens per argumentation feedback comment 
Table 4

Comparison of Frequency Data

\begin{tabular}{lcccc}
\hline Corpus material & $\begin{array}{c}\text { Number of } \\
\text { texts }\end{array}$ & $\begin{array}{c}\text { Number of words: } \\
\text { tokens }\end{array}$ & $\begin{array}{c}\text { Number of } \\
\text { words: types }\end{array}$ & $\begin{array}{c}\text { Average no. of } \\
\text { words/text }\end{array}$ \\
\hline Argumentation feedback corpus & 49 & 16,600 & 1,064 & 338 \\
Feedback corpus (Ädel, 2017) & 375 & 41,776 & 3,618 [average] & 111 [average] \\
\hline
\end{tabular}

The average number of words in feedback comments provided per text in the argumentation feedback corpus AFBK1 was just over three times that in Ädel's corpus. This seems especially high when one considers that this corpus comprised only comments related to argumentation. However, this researcher's feedback strategy was to provide comprehensive scaffolding of argumentation, and as such the comments used would have included high numbers of tokens. The number of word types, as shown in Table 4, is small compared to the number of word tokens in both corpora, indicating the repetition of vocabulary that is common in teacher feedback.

In addition to a comparison of corpora, quantitative and qualitative analysis was conducted on AFBK1 corpus alone to explore how the researcher's feedback comments (teacher as writer and student as reader) realised: i) the reader's response (teacher as reader and dialogue partner); and ii) a pedagogical response (teacher as knowledge resource) to the writer's (student as writer) argumentation in the text at the micro level of the proposed framework within the dialogic feedback process outlined in Figure 1 and 3 above. Instances of potential metadiscourse were identified through a combination of manual analysis and software NVivo 11 (2016) and WordSmith Tools v.7 (Scott, 2017).

As in Ädel's (2017) approach, first and second person pronouns, references to author* and reader*, and References to Text/Code (Ädel, 2006) were searched for. To measure the reader response role that had been adopted, first and second person pronouns, and the nominal references author and reader were considered. The following indicators and terms were considered in the analysis: indicators of a pedagogical response were essay, paragraph*, sentence*, and concept terms were idea*, logic*, argument*, develop* as References to Text/Code that specifically referenced the development of ideas in the text. The code gloss mean*, (e.g. I think what you mean is...) and endophoric references pointing to the current text and other elements/links in the feedback genre chain were also searched for (e.g. Look back at the feedback on your first paragraph). Code glosses add information by rephrasing, elaborating or explaining to recover writer's intended meaning; endophoric references are interactive resources to refer to other parts of the text (Hyland, 2005a). Any combinations (e.g. in your second paragraph ...) were coded separately for the quantitative analysis. 


\section{Findings}

\section{Responding as Reader and Dialogue Partner}

In order to promote awareness of the metadiscursive nature of academic writing, the researcher's feedback strategy involved the explicit signalling of the dialogue partnership between writer and reader. First and second person pronouns, I, me, you, we, my, your, our, were searched for initially, as markers of reader response in the feedback comments. Some of the examples of their use included references to dialogue partnership, as "In your cover sheet, you wrote that you were confused about ...", which functioned intertextually to endophorically reference other elements of the supporting feedback chain beyond the current text. As this was a key strategy in the framework, and additionally realised writer/reader interactivity within the broader feedback discourse, it was important to include these. However, examples of this type are counted separately in the frequency tables below; the use of endophoric markers to reference planned classroom scaffolding or parts of the current text, as part of a pedagogical response, is discussed further in the next section.

Table 5 and Table 6 present the raw frequencies of the personal pronouns in metadiscursive units across the corpus AFBK1. Raw and relative frequencies across the two corpora, AFBK1 and Ädel's are shown in Table 7.

Reader response was most explicitly marked in the examples of the use of personal pronoun $I$ in the corpus. The first person pronoun me was also used in this way but far less frequently. Although use of you was more frequent, this was typically used to refer to current text structure and to provide rationalisation and/or explicit solutions for revision; in other words, as a pedagogical response. The use of we was rare

Table 5

Frequencies for Metadiscursive Use of I, Me, You, and We in AFBK1 Corpus with Examples

\begin{tabular}{|c|c|c|c|c|c|c|c|}
\hline I & & me & & you & & we & \\
\hline$n$ & Example & $n$ & Example & $n$ & Example & $n$ & Example \\
\hline 84 & $\begin{array}{l}\text { When I read this, } \underline{I} \\
\text { feel like I'm reading } \\
\text { a shopping list of } \\
\text { points ... } \\
\underline{\text { I can clearly see }} \\
\text { your development } \\
\text { of idea here - well } \\
\text { done! }\end{array}$ & 18 & $\begin{array}{l}\ldots \text { and then explain } \\
\text { to me how Kelly's } \\
\text { support for women } \\
\text { connects to Legge's } \\
\text { observation }\end{array}$ & 394 & $\begin{array}{l}\text { You've got more } \\
\text { than } 1 \text { controlling } \\
\text { idea here }\end{array}$ & 1 & $\begin{array}{l}\text {...we need to speak } \\
\text { about how you've } \\
\text { used this resource }\end{array}$ \\
\hline $0^{*}$ & & & & 11 * & $\begin{array}{l}\text { Like you, I found } \\
\text { this section hard to } \\
\text { follow** }\end{array}$ & $4^{*}$ & $\begin{array}{l}\text { Look at the work we } \\
\text { did on structuring } \\
\text { arguments in your } \\
\text { paragraph - TEEL* }\end{array}$ \\
\hline 84 & & & & 405 & & 5 & \\
\hline
\end{tabular}

Note. ${ }^{*}$ Endophoric use to refer to other elements in feedback discourse chain.

Note. **Reference to comment student made on their interactive cover sheet 
and only found once in endophoric references to the current text and four times in references to designed-in scaffolding in the in-task guidance phase of the cycle. All these examples realised a pedagogical response.

Table 6

Frequencies for Metadiscursive Use of My, Your, and Our

\begin{tabular}{|c|c|c|c|c|}
\hline my & Example & your & Example & our \\
\hline $\mathrm{n}$ & & $n$ & & $n$ \\
\hline 10 & $\begin{array}{l}\text { Refer to my earlier comments on your use } \\
\text { of logical connectives Amy }\end{array}$ & 385 & $\begin{array}{l}\text { The majority of your supporting sentences are } \\
\text { just specific evidence }\end{array}$ & 0 \\
\hline $0^{*}$ & & $22 *$ & On your cover sheet ... & $0 *$ \\
\hline 10 & & 407 & & 0 \\
\hline
\end{tabular}

Note. ${ }^{*}$ Endophoric use to refer to other elements in feedback discourse chain.

Possessive pronouns were also almost exclusively used pedagogically in reference to the current text, either pointing to earlier feedback comments (e.g. "See my earlier comments"), or providing explanations for problems with argumentation (e.g. "Your use of 'however' is illogical here Steven. This is not a relationship of contrast"). Only your was used endophorically to point back to other elements in the feedback discourse, usually to refer to the students' comments on their interactive self-evaluation cover sheets. No examples of metadiscursive use of our were found in the corpus.

Table 7 presents the raw and normalised (per 1,000 words) frequencies of personal pronouns in AFBK1 in comparison to Ädel's (2017) feedback corpus. Frequencies are normalised per 1,000 words because of the small size of the corpora. It can be seen that the visibility of personal pronouns is similar across the two corpora in the normalised frequencies with the exception of your, which is higher in the AFBK1 corpus. This can be attributed, however, to the extensive use of this possessive pronoun to refer endophorically to other elements in the discourse chain as part of the overall feedback strategy.

Table 7

Comparison of Frequencies of Personal Pronouns in Metadiscursive Units across Corpora

\begin{tabular}{|c|c|c|c|c|c|c|c|c|c|c|c|c|}
\hline $\begin{array}{l}\mathrm{C} \text { o r p u s } \\
\text { material }\end{array}$ & I & & you & & we & & my & & your & & our & \\
\hline & $n$ & $f / 1,000$ & $n$ & $\mathrm{f} / 1,000$ & $n$ & $\mathrm{f} / 1,000$ & $n$ & $\mathrm{f} / 1,000$ & $n$ & $\mathrm{f} / 1,000$ & $n$ & $\mathrm{f} / 1,000$ \\
\hline $\begin{array}{l}\text { A F B K } 1 \\
\text { corpus } \\
(16,600)\end{array}$ & 84 & 5 & 405 & 24 & 5 & $<1$ & 10 & $<1$ & 407 & 24 & 0 & 0 \\
\hline $\begin{array}{l}\text { F e e d b a c k } \\
\text { corpus } \\
(41,776) \\
(\text { Ädel, 2017) }\end{array}$ & 237 & 6 & 1,094 & 26 & 71 & 2 & 54 & 1 & 413 & 10 & $<1$ & $<1$ \\
\hline
\end{tabular}

Nominal references to reader* and author* were also searched across the corpus. There were no examples of author*, however. The noun reader $(n=111)$ was used as an alternative to $\mathrm{I} / \mathrm{me}$ to indicate a general reference to "a" reader's response and/or a 
specific reference to "the" reader's (i.e. of the current text) response, as in examples (1), (2) and (3). As identified by Ädel (2017), this concurrent general and specific referencing, adds to the complexity of metadiscourse use in feedback. Table 8 shows a comparison of occurrences of these nominal references between AFBK1 and Ädel's corpus.

(1) This makes it very confusing for your reader

(2)... as your reader, I must be able to ...

(3)...to make a link for the reader ...

\section{Responding as Teacher and Knowledge Resource}

Pedagogical feedback responses as interactional contingent scaffolding referenced the current text and the designed-in scaffolding of the in-task guidance phase of the dialogic feedback cycle. Uses of metadiscourse here were highly reader-oriented (student as reader - teacher as writer), directing action for revision.

Table 8

Comparison of Frequencies of Nominal References Reader* and Author* in Metadiscursive Units across Corpora

\begin{tabular}{|c|c|c|c|c|}
\hline Corpus material & reader(s) & & author(s) & \\
\hline & $n$ & $\mathrm{f} / 1,000$ & $n$ & $\mathrm{f} / 1,000$ \\
\hline $\begin{array}{l}\text { AFBK1 corpus } \\
(16,660)\end{array}$ & 111 & 7 & 0 & 0 \\
\hline $\begin{array}{l}\text { Feedback corpus } \\
(41,776) \\
(\text { Ädel, } 2017)\end{array}$ & 92 & 2 & 12 & $<1$ \\
\hline
\end{tabular}

References to Text/Code and concept terms that specifically referenced argumentation in the text, as illustrated in examples (4) to (9), were recurrent throughout the corpus. References to current text were mainly to identify problems, as in examples (4) and (6), suggest solutions, as in examples (7) and (8), and provide rationale, as in examples (5) and (9). There were also examples of positive response (e.g. Nice concluding sentence linking back to your thesis), although less common.

(4) Which of these is the thesis for your essay?

(5) A topic sentence needs a clear controlling idea.

(6) I can't see the relationship between your ideas here Owen.

(7) ... better logical connectives would help to develop your idea here ...

(8) ... start a new paragraph ...

(9) "However" is illogical here at the beginning of the sentence as the reader would

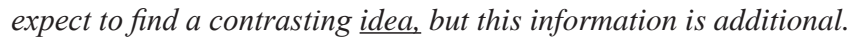


References to designed-in scaffolding, as in examples (10) and (11), were used to direct students to resources for revision solutions from the in-task guidance phase of the cycle, in the earlier part of the feedback chain.

(10) Look back at the work we did on paragraph structure in week 4.

(11) Review the activities on developing an argument in your paragraphs.

Frequencies of references to the current text and to earlier parts of the feedback discourse chain are shown in Table 9. Raw and normalised frequencies for totals are also provided for comparison with Ädel's (2017) corpus for similar text/codes.

Table 9

Frequencies of References to Text (Pedagogical Response to Argumentation)

\begin{tabular}{lcccccc}
\hline $\begin{array}{l}\text { References } \\
\text { Text/Code } \\
\text { and concept terms }\end{array}$ & to Current text & $\begin{array}{c}\text { Endophoric reference to } \\
\text { designed-in scaffolding }\end{array}$ & Total & $\begin{array}{c}\text { AFBK1 } \\
\text { corpus } \\
(16,660)\end{array}$ & $\begin{array}{c}\text { Feedback corpus } \\
(41,776) \\
(\ddot{A d e l}, 2017)\end{array}$ \\
\cline { 2 - 7 } & $\mathrm{n}$ & $\mathrm{n}$ & $\mathrm{n}$ & $\mathrm{f} / 1,000$ & $\mathrm{n}$ & $\mathrm{f} / 1,000$ \\
\hline essay & 55 & 19 & 74 & 4 & 92 & 2 \\
paragraph* & 229 & 32 & 261 & 16 & 230 & 5 \\
sentence* & 75 & 23 & 98 & 6 & 386 & 9 \\
idea* & 181 & 17 & 198 & - & - & - \\
logic* & 32 & 26 & 58 & - & - & - \\
argument* & 53 & 73 & 126 & - & - & - \\
develop* & 97 & 34 & 131 & - & - \\
Total & 722 & 224 & 946 & & & - \\
\hline
\end{tabular}

With the exception of argument*, the frequency of references to current text was much higher than to the designed-in scaffolding in the earlier phase of the feedback genre. Problems with development of argument/argumentation were often collocated with develop* in the corpus and appeared to require more "hand-holding" type (increased explicitness and rationale) comments (Mahboob, 2015), and thus more direction to refer back to earlier resources. References to paragraph* were much higher in the AFBK1 corpus than Ädel's (2017) feedback corpus, evidencing the specific pedagogical focus of the comments in the AFBK1 corpus.

The code gloss mean* was also searched for in the corpus $(n=12 ; \mathrm{f} / 1,000=<1)$. Examples showed a similar use to Ädel's (2017) analysis $(n=109 ; \mathrm{f} / 1,000=3)$ revealing its function for negotiating meaning; however, in the AFBK1 corpus, this code gloss was exclusively used to refer to the logic of the development of ideas in the current text. As with other pedagogically-oriented feedback, the comments indicate the action students could take to improve their text either by explicitly suggesting a solution, as in example (13), or implicitly doing so, as in examples (12) (14) and (15), thereby "returning the dialogue" to the student and thus increasing "prospectiveness" (Hammond \& Gibbons, 2005; Wells, 1996). 
(12) Fashion itself is not a problem. I think you mean how to define fashion is the problem.

(13) You need to explain what you mean by "people believed in carpe diem”...

(14) What did this mean for the transformation of this period?

(15) Do you think this meant the impact was not so important then?

Evidence of Socratic questioning as in examples (14) and (15) was infrequent. In Mahboob's (2015) typology, these types of feedback comments are categorised as "base jumping" providing low explicitness and low rationale, hinting at what may be needed to improve. Their use is identified as "risky" unless students can understand the "what, why and how" in order to respond successfully, which was the case for this text.

The findings show the ways in which endophorics variously directed attention towards the current text or the wider feedback discourse chain. Frequencies of endophorics used deictically to point to a specific area of the current text or imperatively to instruct students to refer to previous feedback (either given on the current text or in earlier phases of the process) were high, and this finding concurs with Ädel's (2017) observations. The four main endophorics used were here, see, look and review. Frequencies for these endophorics are shown in Table 10. Normalised frequencies for here are also provided, for comparison with Ädel's (2017) feedback corpus.

Table 10

Frequencies for Main Endophorics: Here, See, Look and Review

\begin{tabular}{lcccccc}
\hline Endophorics & $\begin{array}{c}\text { Reference to } \\
\text { current text }\end{array}$ & $\begin{array}{c}\text { Reference to designed- } \\
\text { in scaffolding }\end{array}$ & \begin{tabular}{c} 
Total \\
\cline { 2 - 6 }
\end{tabular} & $\begin{array}{c}\text { AFBK1 corpus } \\
(16,600)\end{array}$ & $\begin{array}{c}\text { Feedback corpus (41,776) } \\
\text { (夰del, 2017) }\end{array}$ \\
\hline here & 32 & $n$ & $n$ & $\mathrm{f} / 1,000$ & $n$ & $\mathrm{f} / 1,000$ \\
see & 20 & 0 & 32 & 2 & 272 & 6 \\
look & 0 & 3 & 23 & - & - & - \\
review & 0 & 11 & 11 & - & - & - \\
\hline
\end{tabular}

(16) I can't understand the connection here Joy.

(17) See my earlier comments about unclear referents.

(18) Look back at work we did in week 6 on introductions.

(19) Review the examples of paragraph structure we looked at in week 5.

The endophorics here and see were extensively used to refer to the current text. The endophoric here was solely used to point to a specific aspect of the current text, as in example (16), whereas see was mainly used to point back to earlier comments on the current text, as in example (17); look and review, as in examples (18) and (19) were used to point back to earlier resources in the designed-in scaffolding. 


\section{Summary}

Ädel $(2017,2018)$ has called for analysis of larger corpora to investigate her important findings and assess variation of feedback across a larger group of teachers. This study has compared her findings to those from this researcher's own feedback practice and, as such, has utilised a much smaller corpus. Despite this, however, the findings re-enforce her suggested implications for revisions in the definition and modelling of metadiscourse in the context of a principled feedback framework. A dialogic feedback practice, where feedback as a supporting genre is realised as part of a cyclical process, requires that the interpersonal relationship -the dialogic partnership between reader and writer- is fluid and extends beyond just that of "current text". As participants in a feedback discourse community, both student and teacher have agency and visibility as writers and/or readers of feedback, making these roles within this feedback genre particularly complex.

The reciprocity of this writer/reader relationship in feedback also reflects the interactivity of argumentation, where awareness of audience is essential in successful criticality in writing. Comments in the role of dialogue partner provided feedback that emphasised the "personal" response of the reader with the use of first person $I$ or specific references to the reader. Comments in the role of "teacher as knowledge resource" had a more explicitly pedagogical function directed towards suggested improvements to the text by realising rhetorical consciousness and metadiscoursal awareness. Here, the student as writer was foregrounded through the use of second person pronouns you/your, and with general references to reader which drew attention to the expectations of a wider discipline audience. These comments also referenced other elements in the feedback supporting chain.

Feedback praxis is typically individualised and informed by many variables. Variation in the metadiscourse use shown in this study, therefore, is reflective only of the specific materials and practices in the context of this sample. The insights provided by undertaking the metadiscourse analysis in this study have, nevertheless, highlighted the pragmatics that underpin the proposed praxiology for a dialogic feedback practice to improve students' argumentational skills in L2 writing.

\section{References}

Ädel,A. (2018). Variation in metadiscursive 'you' across genres: From research articles to teacher feedback. Educational Sciences: Theory \& Practice, 18, 777-796. http://dx.doi.org/10.12738/estp.2018.4.0037

Ädel, A. (2017). Remember that your reader cannot read your mind: Problem/solution-oriented metadiscourse in teacher feedback on student writing. English for Specific Purposes, 45, 54-68. http://dx.doi.org/10.1016/j.esp.2016.09.002

Ädel, A. (2006). Metadiscourse in L1 and L2 English. Amsterdam, NL: John Benjamins Publishing. Andrews, R. (2010). Argumentation in higher education. Improving practice through theory and research. London, UK: Routledge. 
Aull, L., \& Lancaster, Z. (2014). Linguistic markers of stance in early and advanced academic writing: A corpus based comparison. Written Communication, 31, 151-183. http://dx.doi. org/10.1177/0741088314527055

Bacha, N. N. (2010). Teaching the academic argument in a university EFL environment. Journal of English for Academic Purposes, 9, 229-241. http://dx.doi.org/10.1016/j.jeap.2010.05.001

Bublitz, W.(1999). Views of coherence. In W. Bublitz, U. Lemk, \& E. Ventola (Eds.), Coherence in spoken and written discourse: How to create it and how to describe it (pp. 1-11). Amsterdam, NL: John Benjamins.

Coffin, C., \& Donohue, J. (2014). A language as social semiotic-based approach to teaching and learning in higher education. Chichester, UK: John Wiley \& Sons.

Fenton-Smith, B., Humphreys, P., \& Walkinshaw, I. (2017). On evaluating the effectiveness of university-wide credit-bearing English language enhancement courses. Journal of English for Academic Purposes, 31(1), 72-83. http://dx.doi.org/10.1016/j.jeap.2017.12.001

Fenton-Smith, B., Humphreys, P., Walkinshaw, I., Michael, R., \& Lobo, A. (2015). Implementing a university-wide credit-bearing English language enhancement programme: Issues emerging from practice. Studies in Higher Education, 42(3), 463-479. http://dx.doi.org/10.1080/03075079.2015.1052736

Goldstein, L. M. (2005). Teacher written commentary in second language writing classrooms. Ann Arbor, MI: University of Michigan Press.

Hammond, J., \& Gibbons, P. (2005). Putting scaffolding to work: The contribution of scaffolding in articulating ESL education. Prospect: An Australian Journal of Teaching/Teachers of English to Speakers of Other Languages (TESOL), 20(1), 6-30.

Hyland, K. (2001). Bringing in the reader: Addressee features in academic articles. Written Communication, 18, 549-574.

Hyland, K. (2004). Patterns of engagement: dialogic features and L2 undergraduate writing. In L. J. Ravelli \& R. Ellis (Eds.), Analysing academic writing: Contextualised frameworks (pp. 5-23). London, UK: Continuum.

Hyland, K. (2005a). Metadiscourse: Exploring interaction in writing. London, UK: Continuum.

Hyland, K. (2005b). Representing readers in writing. Student and expert practices. Linguistics and Education, 16, 363-377.

Hyland, K. (2016). Teaching and researching writing (3rd ed.). Oxon, UK: Routledge.

Mahboob, A. (2015). Understanding and providing 'cohesive' and 'coherent' feedback on writing. Writing and Pedagogy, 7(2), 401-422.

Rodway, C. (2017a). Encouraging active participation in dialogic feedback through assessment as learning. Journal of Response to Writing, 3(2), 74-92.

Rodway, C. (2017b). Opening up dialogic spaces: Rethinking the prescriptive paragraph structure in L2 writing pedagogy. Asian EFL Journal, 19(1), 130-158.

Swales, J. M. (1990). Genre analysis: English in academic and research settings. Cambridge, UK: Cambridge University Press.

Vines, A. (2009). Multivoiced e-feedback in the study of law: Enhancing learning opportunities? In R. Krumsvik (Ed.), Learning in the network society and the digitized school (pp. 225-255). New York, NY: Nova Science.

Wells, G. (1996). Using the tool-kit of discourse in the activity of learning and teaching. Mind, Culture and Activity, 3(2), 74-101. http://dx.doi.org/10.1207/s15327884mca0302_2

Wingate, U. (2012). 'Argument!' Helping students understand what essay writing is about. Journal of English for Academic Purposes, 11(1), 145-154. http://dx.doi.org/10.1016/j.jeap.2011.11.001 